\title{
"Poly Chords"
}

Fatima Mahmoud Al-Jarsha

Abstract:

The chord is several tones that are heard at the same time, and they are either of three types $(\mathrm{k}$, $r, z, n)$ in its basic situation or its various upheavals, or the four of its five types, as classified by Dalcruz

All of these combinations are heard individually up to the master's level.

التآلف عدة نغمـات تسمع في آن واحدد ، وهـي إمـا ثلاثية بأنواعها ( ك ، ص ، ز ، ن ) فـي

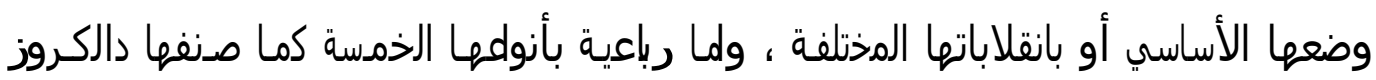

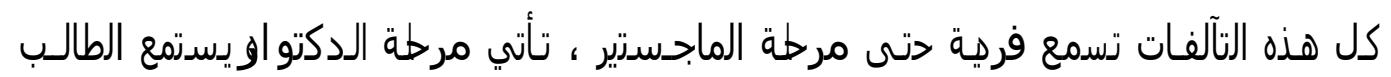
إلى التعددية في كل من :

أ- تعدد السـلالم "Poly Tonality" أي عـزف ســمين فـي وقت واحـد ســواء كانوا متشابهينفي

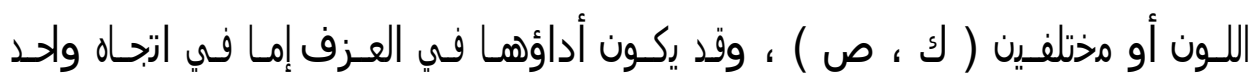

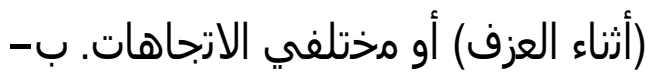

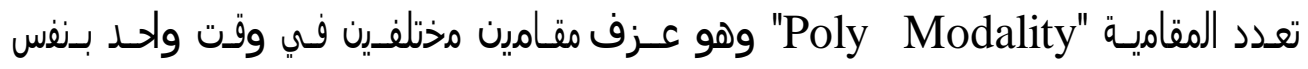
الأداء السابق. ج- تعدد التآلفـات "Poly Chords" وهو سـماع أكتــر مـن تـآلفين هـاروونيرن في وقت واحــ متشابهة أو مختلفة في اللون على درجات ومناطق صـوتية مختلفة ولتي تزيد في رينها من 
حدة التوتر والإثارة ، ولها عـدة أشـكال وتكوينات مـن الممكن أن تظهر بوجـود تآلفين

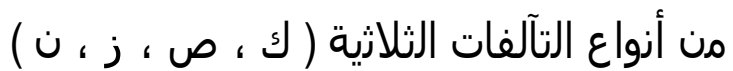

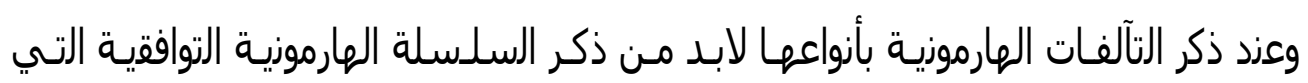
ترتبع التآلفات العارموزية "Overtones" : د- السلـسلة الهارمونيـة التولقيـة "Overtones" ، يطلـق عليهـا السلـسلة الهاروونيـة التولقيـة

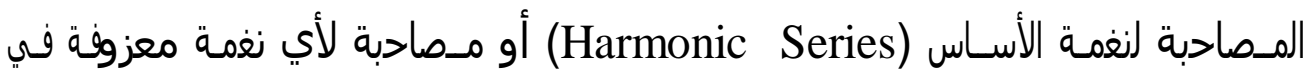

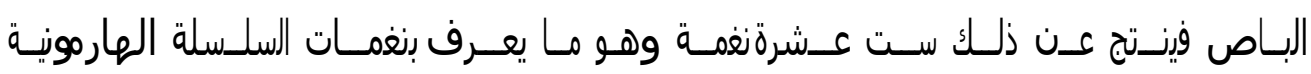
التوافقية كما في الشدل رة (1)

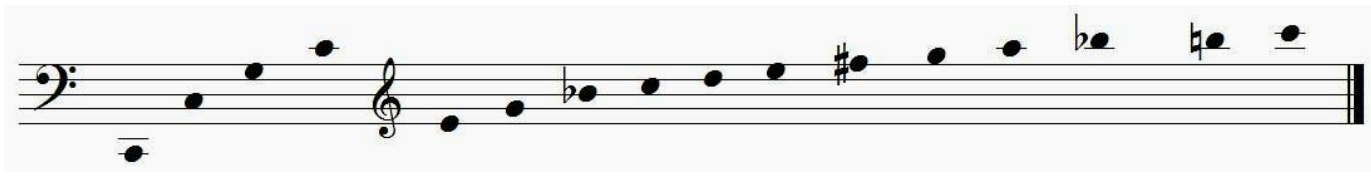
شكل رة (1)

نغمات السلسلة الهارمونية التوافقية

1. Westrup. Jackand F.Li Harrison Collins pocket Dictionary of music. 
" اسدزخدامات التآلفات المتعددة "Poly Chords" تظهر بداية التآلفات المتعددة من خلال ظعور النغمـات الممتـدة (Pedal Notes) كمـا

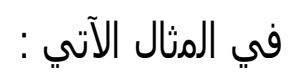

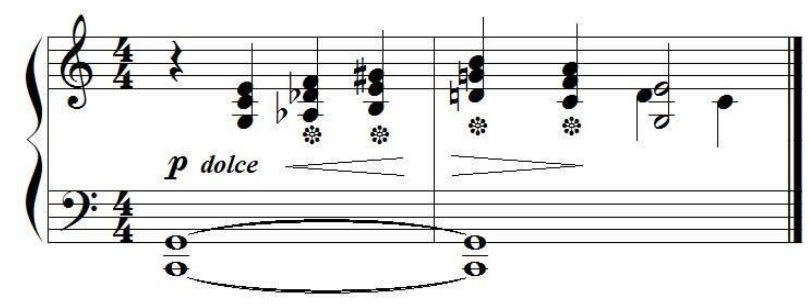

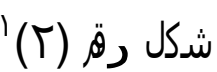

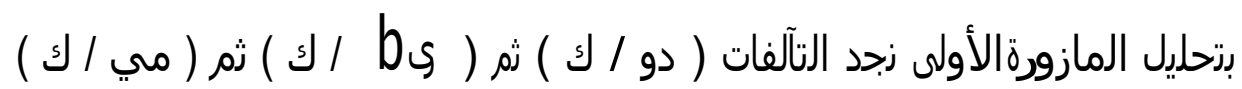

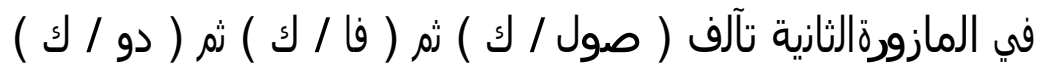

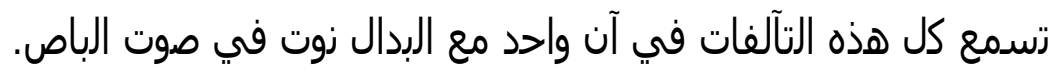
ملحوظة : الشكل رة (T) يصلح للإملاء لطالب الدكتو او. والتآلفات الهارمونية المتعـدةر (Poly Chords) تظهـر في سـلالم منفـصلة كمـا في شكل رة (ז) تآلف (رى/ ك) في الصوت الأعلى وتآلف (فا / ك) في الصوت الأسفل.

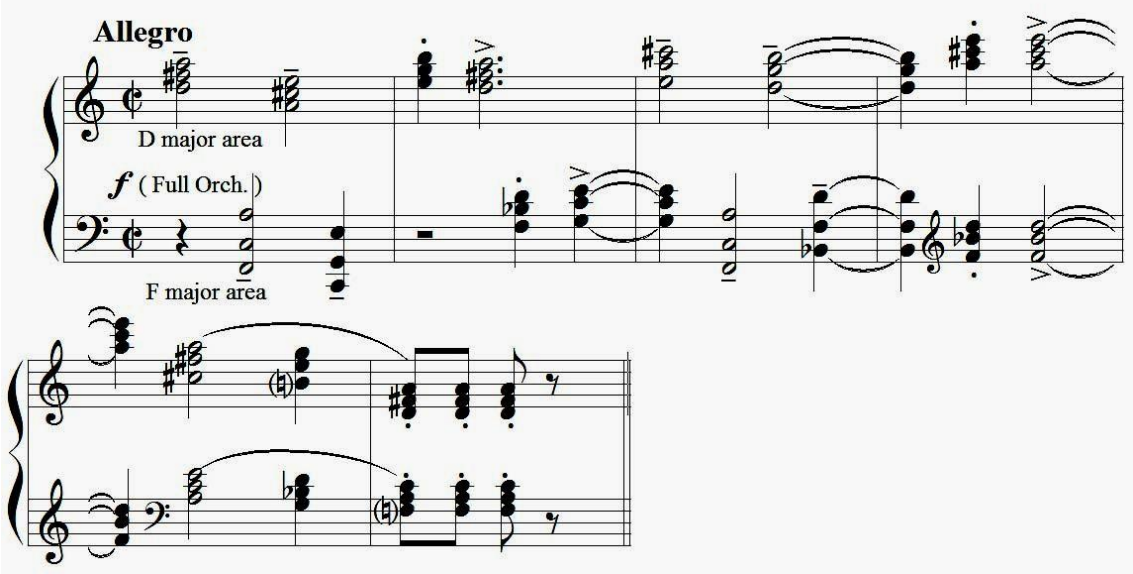

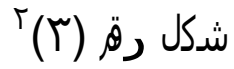

والـشكل رقم (זّ) مثــال تآلفــات متعـددة تــصلح للاسـزخدام فـي القـصص الموسـيقية الحركية لشدة الرتافر في زكوينها. وغالبًّالا زترت التآلفات الهارمونية المتعددة على شـل واحد كما يظهـر في الشكل رقم 
INTERNATIONAL JOURNAL OF

CREATIVITY AND INNOVATION IN HUMANITIES AND

\section{EDUCATION}

ISSN: $2735-4393$

VOLUME 4, ISSUE 1, 2021, 54-63.

www.egyptfuture.org/oj

s/

1. Greet Britain- wm. Collins Sons \& Co. Ltd. 1984. p. 213.

2 - Persiehetti, Vincent Twentieth Century Harmony Creative Aspects and Practice, U.S.A. Vol. 1, Ballou Press, Inc. 1967. P. 139 


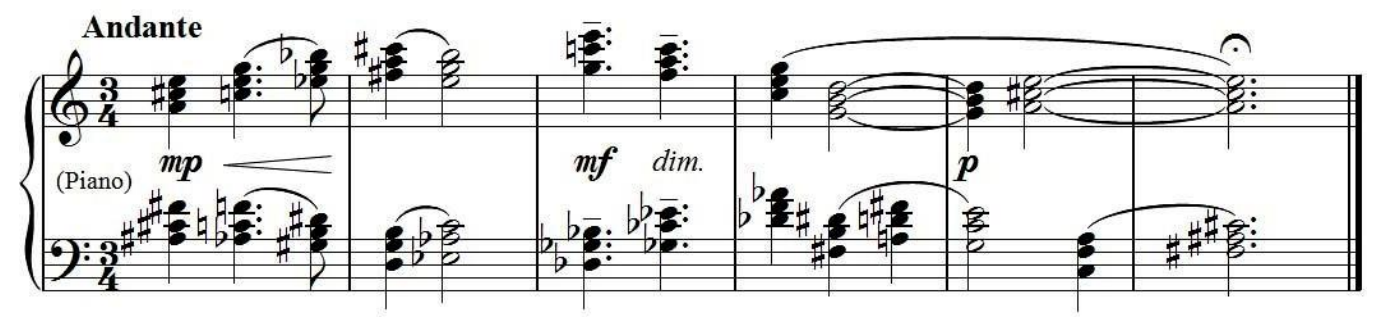

شكل رة (ع) (1)

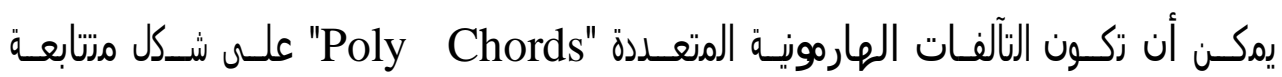

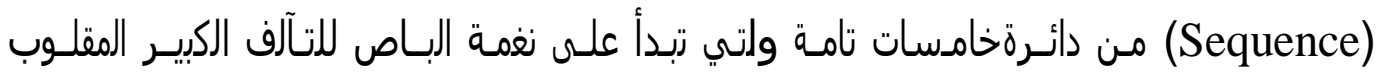
قلب ثان كما في شكل رةر (0)

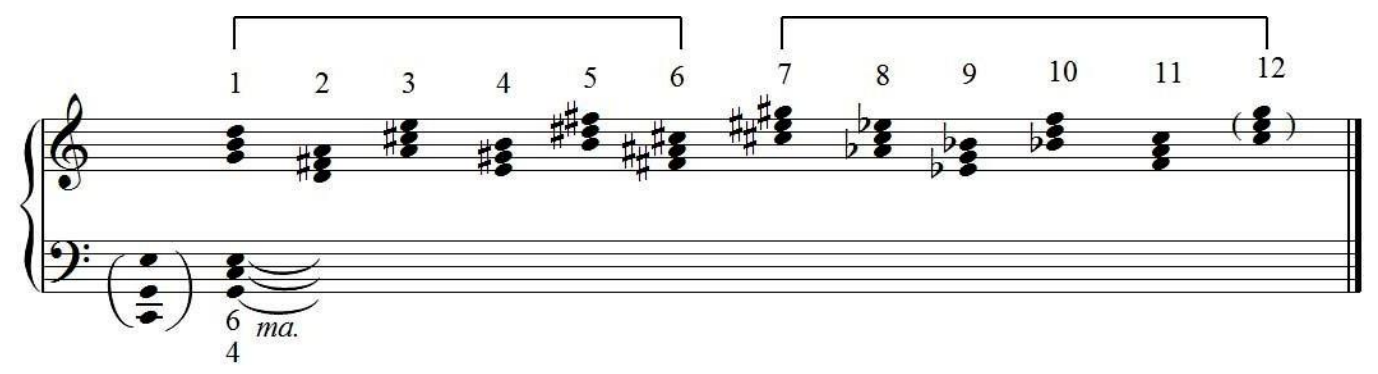

شدكل رقة (0)

يمكن بناء تآلفات هارمونية متعددة في تتابع دائرة خامسات تامـة مـع بنـاء تآلف صغير

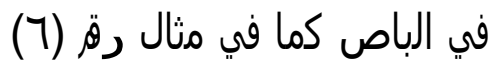

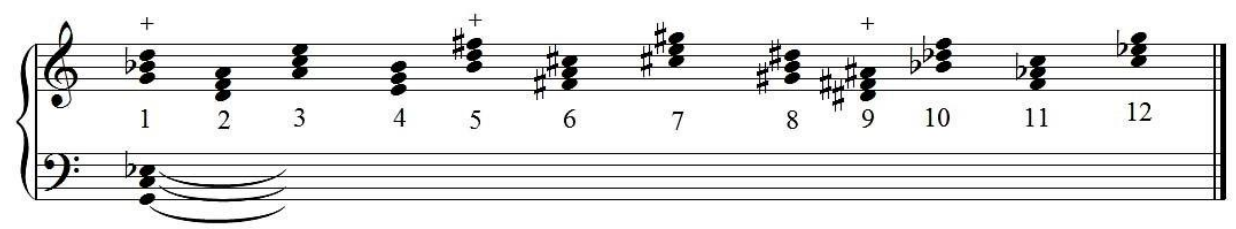

شدل رة (7)

يمكن بناء تآلفات هارمونية متعـدة "Poly Chords" برتكوين تآلفـات صغيرة تسمع فـي

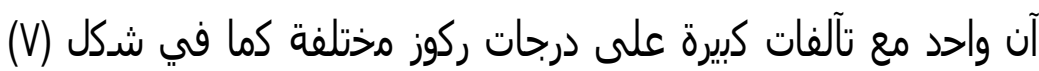

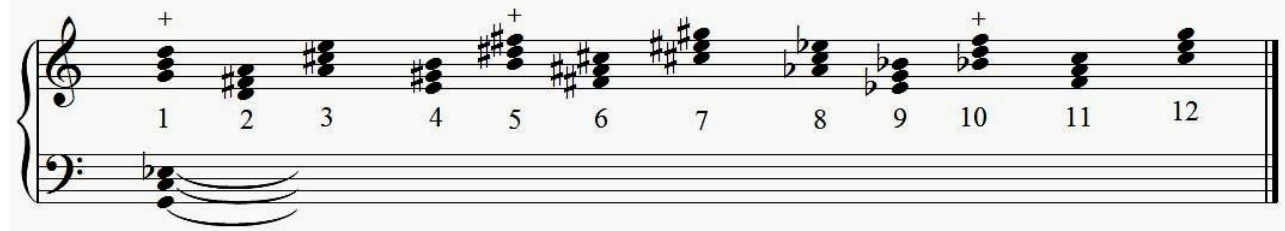

شكل رة 
ازتقال التآلفـات الهاروويـة المتعددة "Poly Chords" في حركة هارمونية لأعلى فإن رينهـا

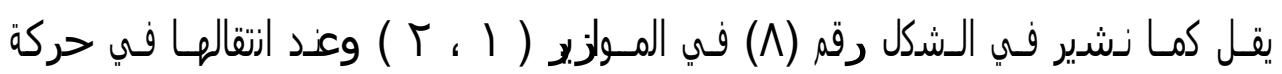

هارمونية لأسفل يظهر العزف والخشونة كما في موازير ( ب ، ع ).

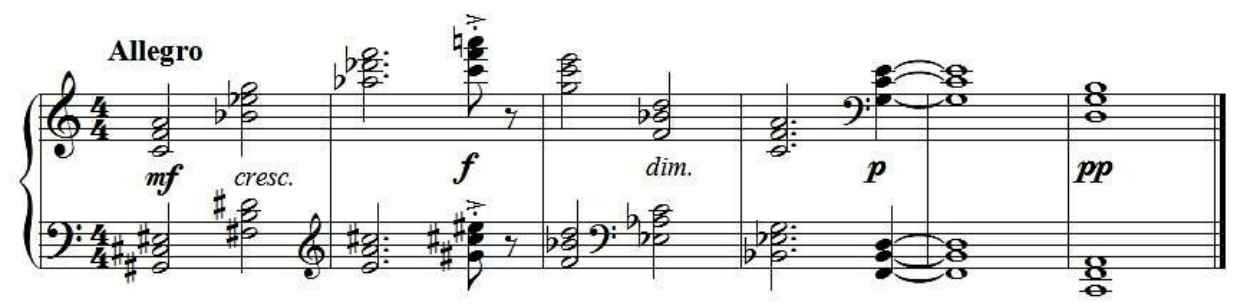

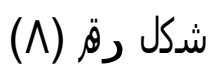

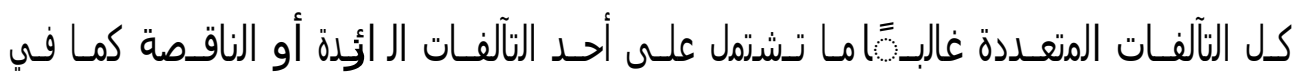

شكل رة (9)

(1)

(2)

(3)

(4)

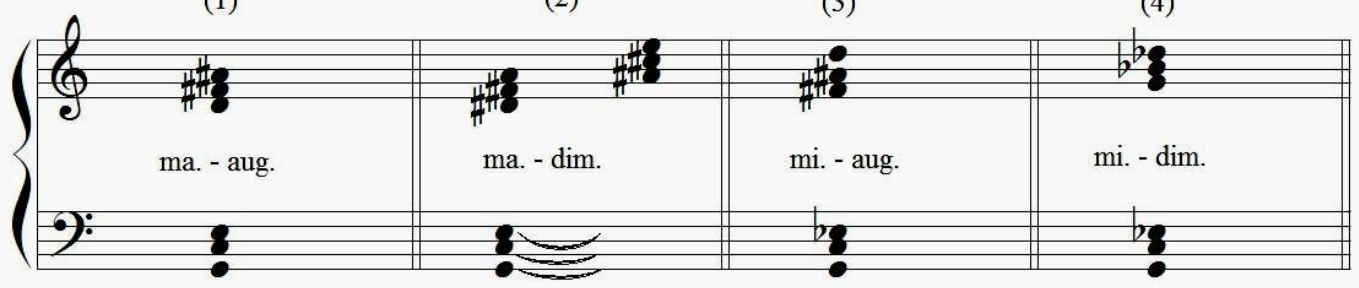

شكل رة (9)

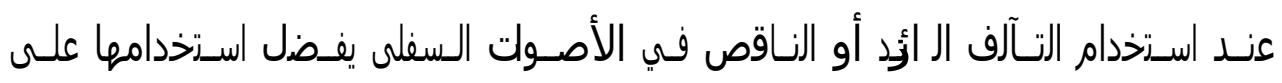

مسافات متباعدة كما في شكل (1•).

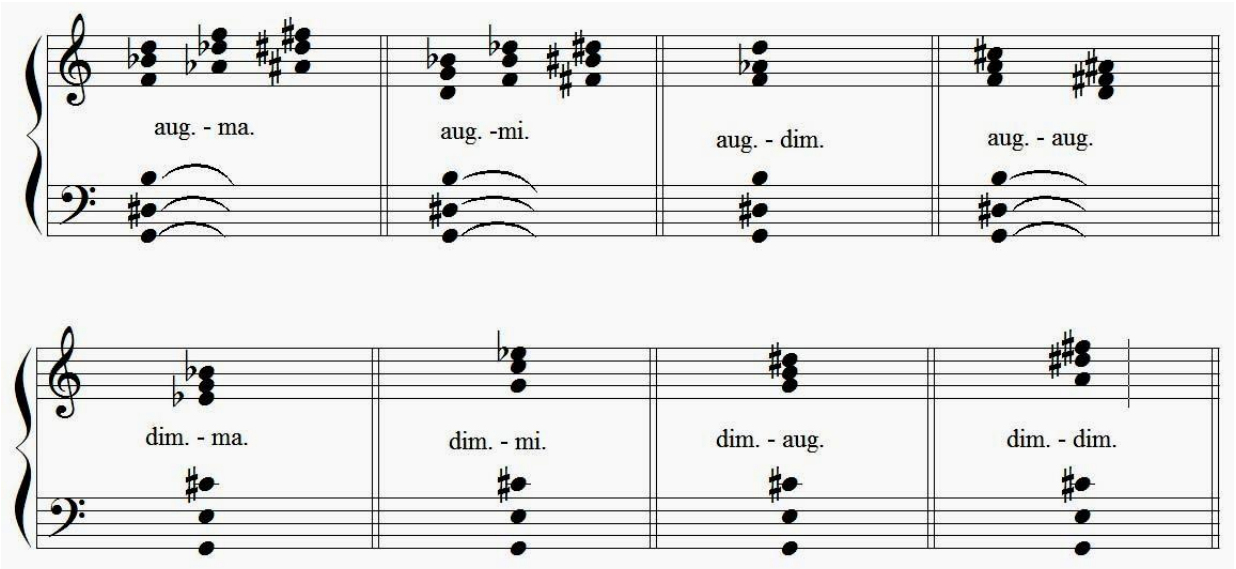

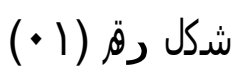

يمكـن بنـاء تآلفـات هارمويـة متعـددة علـى درجات لحزيـة مختلفـة مـن درجات السلسلة

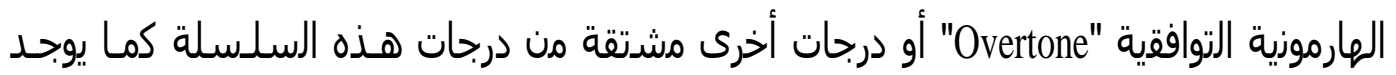


INTERNATIONAL JOURNAL OF

أربعة أزواع من تكوينات التآلفات الهارموزية المتعددة كما يلي : 


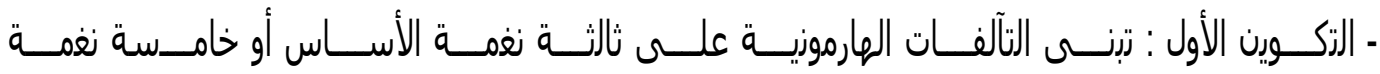

الأساس كما في شكل رة (1)

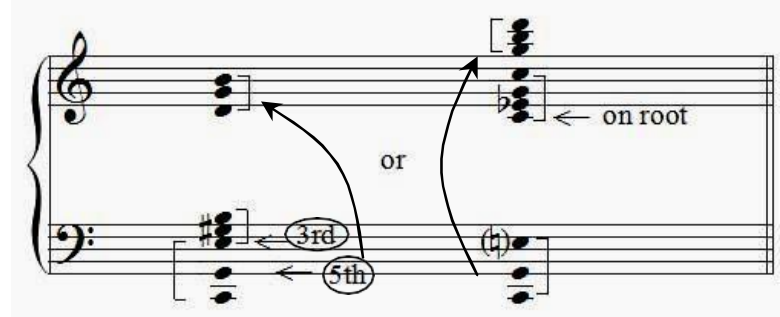

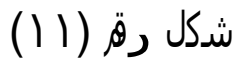

- التكـوين الثاني : يرنـى التآلف علـى خامسة الدرجة الثالثة مـن نغمـة البـاص (سـي) وكذلك

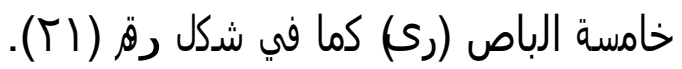

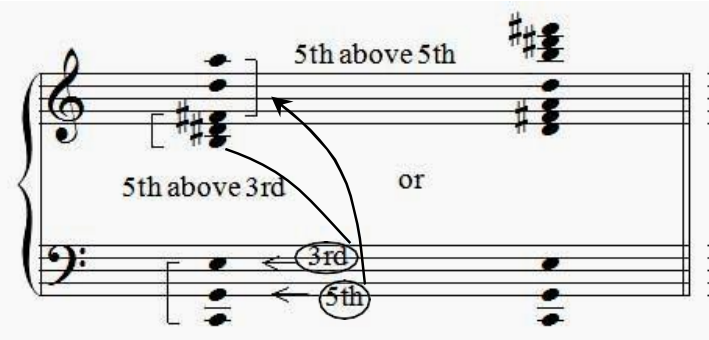

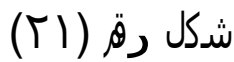

- التكوين الثالث : وفيـه تربنى تآلفـات هارمونية على خامسـة الدرجـة الثالثة مـن نغمـة الباص ، كذلك على خامسة الخامسة لنغمة الباص (لا) كما في شكل رة (آ).

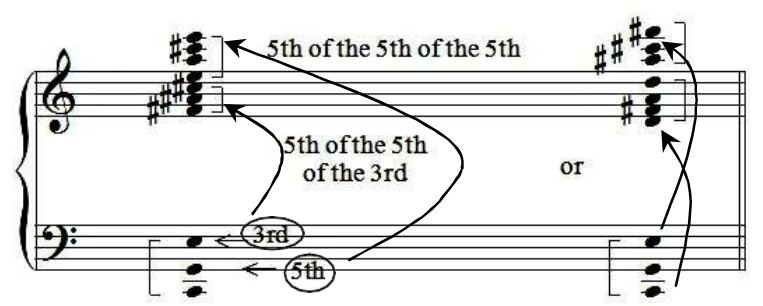

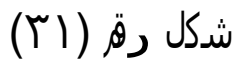

- التكوين ال اهع : ترنى التآلفات العارمونية المتعددة على ثالثة أساس السلسلة التولقية (مي)

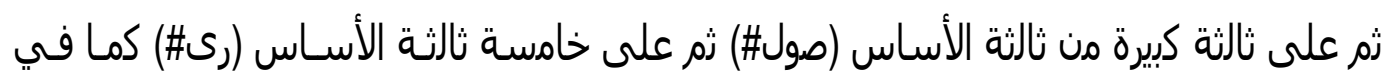

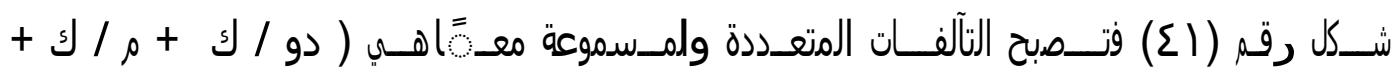

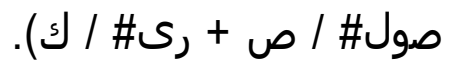




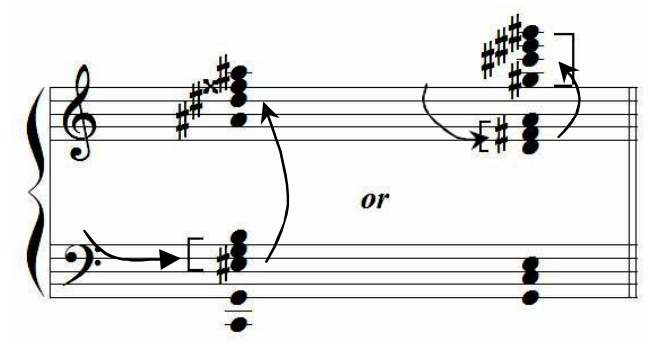

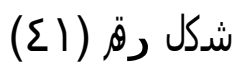

- تظهر التآلفات الهارموزية المتعددة في أكثر من تآلفين يسمعان معاً يعطسي نسيج هـارموني كثرف كما في شكل رثة (1) - (0).

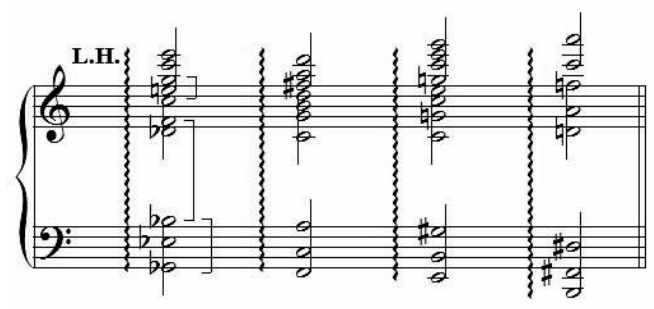

شكل رقة (01) (0)

يوضح الشكل السارق استخدام التآلفات الهارموزية المتعددة في مجمـوعترين مـن التآلفات

، التآلف الأول ( ميل / ص ) ثم تآلف ( ركلم / ز ) ليظعر تآلف ( دو / ك ).

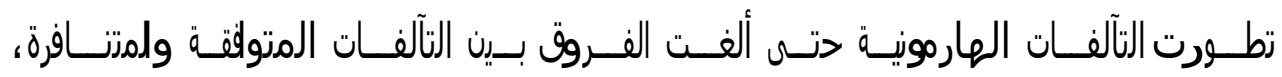

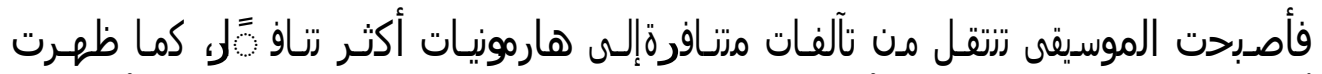

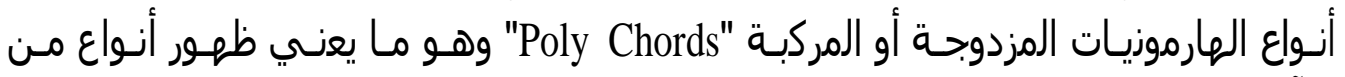
التآلفات المختلفة في وقت واحد.

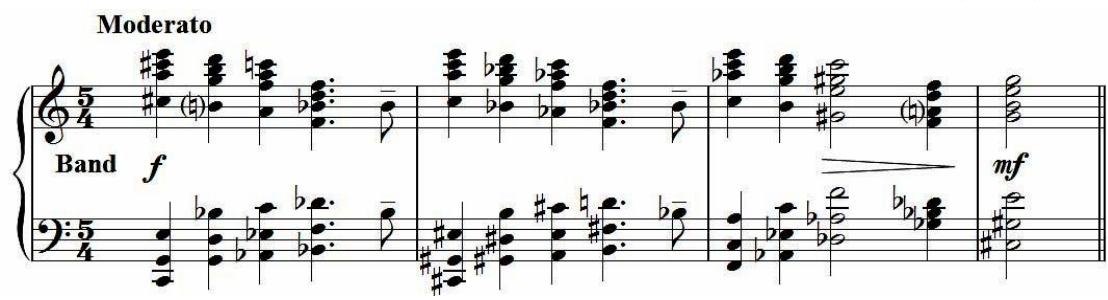

شكل رة (1) (1)

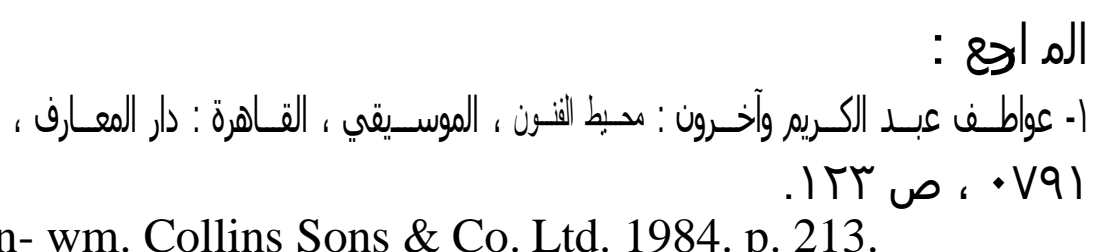

2- Greet Britain- wm. Collins Sons \& Co. Ltd. 1984. p. 213

3- Persiehetti, Vincent Twentieth Century Harmony Creative Aspects and Practice, U.S.A. Vol. 1, Ballou Press, Inc. 1967. P. 139 
INTERNATIONAL JOURNAL OF

4- Westrup. Jack and F.Li Harrison Collins pocket Dictionary of music. 